\title{
Liquid Oxygen - Fire Hazards of Oxygen and Oxygen-Enriched Atmospheres
}

\author{
Roland Wicki*
}

\begin{abstract}
Oxygen, which is essential to life, is not flammable in itself but supports and accelerates combustion. The normal concentration in the air that we breathe is approximately $21 \%$ by volume. Most materials burn fiercely in oxygen; the reaction could even be explosive. As the oxygen concentration in air increases the potential fire risk increases. Being heavier than air, oxygen can accumulate in low lying areas such as pits, trenches or underground rooms. This is particularly relevant when liquid oxygen spills out. In that case the generated cold gaseous oxygen is three times heavier than air. As 1 I of liquid oxygen liberates circa 850 I of gas, the phenomenon of oxygen enrichment is massively amplified by a spill of liquid oxygen, and thus fire risk is increased.
\end{abstract}

Keywords: Combustible material · Cryogenic liquid · Liquid oxygen · Oxygen ·

Oxygen-enriched atmosphere

\section{General Properties}

Oxygen, which is essential to life, is not flammable in itself but supports and accelerates combustion. The normal concentration in the air that we breathe is approximately $21 \%$ by volume.

\subsection{Oxygen Supports and} Accelerates Combustion

Most materials burn fiercely in oxygen; the reaction could even be explosive. As the

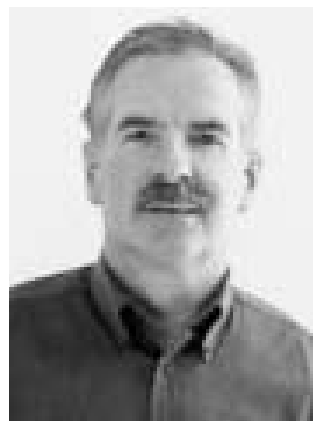

${ }^{\star}$ Correspondence: R. Wicki Safety Manager CARBAGAS

Hofgut

CH-3073 Gümligen

Tel.: +41319505110

Fax: +4131950 5002

E-Mail: roland.wicki@carbagas.ch oxygen concentration in air increases the potential fire risk increases.

\subsection{Oxygen Gives No Warning}

Oxygen is colorless, odorless and tasteless, hence the presence of an oxygenenriched atmosphere cannot be detected by normal human senses. Oxygen also does not give any physiological effects which could alert personnel to the presence of oxygen enrichment.

Increasing the oxygen concentration of the air at atmospheric pressure does not constitute a significant health hazard.

\subsection{Oxygen Is Heavier than Air}

Being heavier than air, oxygen can accumulate in low lying areas such as pits, trenches or underground rooms. This is particularly relevant when liquid oxygen spills out. In that case the generated cold gaseous oxygen is three times heavier than air.

\subsection{Summary of Oxygen Properties}

- Percent by volume in air $21 \%$

- Gas density $\left(\mathrm{kg} / \mathrm{m}^{3}\right.$,

1.013 bar, $\left.15^{\circ} \mathrm{C}\right) \quad 1.36$

- Boiling point $\quad-183{ }^{\circ} \mathrm{C}$

- Liquid density

( $\mathrm{kg} / \mathrm{l}$, at boiling point) $\quad 1.14$

In normal atmospheric conditions 11 of liquid oxygen liberates $c a .8501$ of gas.

\section{Fire Hazards with Oxygen}

\subsection{Necessary Conditions for a Fire}

In general for a fire or explosion to occur three elements are required: combustible material, oxygen, and an ignition source. The 'fire triangle' (Fig. 1) is the normal way of representing these conditions. When one of the three elements is missing a fire cannot occur.

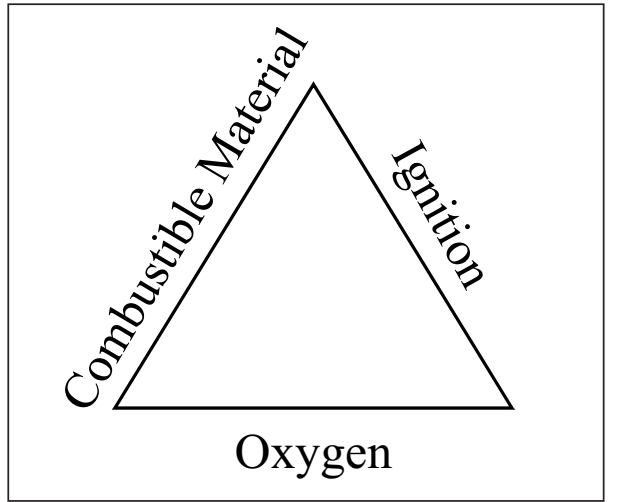

Fig. 1. Fire triangle

\subsection{Oxygen}

Oxygen reacts with most materials. The higher the oxygen concentration and pressure in the atmosphere or in an oxygen system, then:

a) The more vigorously the combustion reaction of fire takes place, 
b) The lower the ignition temperature and the ignition energy to get the combustion reaction started,

c) The higher the flame temperature and destructive capability of the flame.

Causes of oxygen fires can be categorized as follows:

a) Oxygen enrichment of the atmosphere,

b) Improper use of oxygen,

c) Incorrect operation and maintenance of oxygen systems,

d) Use of materials incompatible with oxygen service.

\subsubsection{Oxygen Enrichment of the Atmosphere}

Oxygen enrichment of the atmosphere can be the result of

a) Leaking pipe connections, flanges, etc: This can be particularly hazardous in areas where there is insufficient ventilation causing the oxygen concentration to increase.

b) Breaking into systems under oxygen pressure: A sudden release of oxygen under pressure can result in a relatively large jet of escaping oxygen. This may result in a torching fire.

c) Oxygen use in cutting and welding processes: In process such as cutting, gouging, scarfing and thermic lancing, oxygen is used in quantities greater than necessary for the burning process. The unused oxygen remains in the atmosphere, and if ventilation is inadequate the air can become enriched with oxygen. Effective ventilation and periodic analysis for oxygen content is recommended.

d) Oxygen use in metallurgical processes: Incorrect practice in the use of blowpipes can also lead to oxygen enrichment, especially in confined spaces. Therefore care should be taken:

- to follow correct hose purging and lighting up procedures,

- to avoid delay in lighting the blowpipe after opening the valves,

- to close the valves of the blowpipe and of the gas supply when interrupting or finishing the work,

- to select the correct nozzles and pressures to maintain oxygen hoses leaktight and periodically inspected.

e) Desorption: Oxygen can be released in appreciable quantities when cold materials which have absorbed oxygen such as absorbents (molecular sieve, silica gel, etc.) or insulation materials are warmed to room temperature.

f) Cryogenic liquid spill: A spill of liquid oxygen creates a dense cloud of oxygen-enriched air when evaporating. In an open space hazardous oxygen concentrations usually exist only within the visible cloud associated with the spill. Nevertheless, atmospheric checks should be carried out to confirm this when approaching the vicinity of the vapor cloud.

g) Liquefaction of air: When using cryogenic gases with boiling points lower than oxygen, e.g. nitrogen, hydrogen and helium, oxygen enrichment can also occur. Ambient air will condense on uninsulated equipment where the temperature is lower than the liquefaction temperature of air (approx $\left.-193{ }^{\circ} \mathrm{C}\right)$. This will also occur on pipework lagged with an open cell insulant. The liquid air so produced can contain up to $50 \%$ oxygen and, if this liquid drips off and evaporates, the oxygen concentration in the last remaining portion can be over $80 \%$. Consequently, special precautions must be taken with regard to the potential oxygenenriched insulation and to the vessel before starting repair work on any equipment.

h) Oxygen vents: Particularly hazardous are areas where oxygen vents are located. A sudden release of oxygen can occur without warning. Note that the non-cryogenic production of oxygen or nitrogen might involve an occasional or continuous venting of oxygen.

\subsubsection{Improper Use of Oxygen}

Many serious accidents have been caused by the use of oxygen for applications for which it was not intended.

Examples of improper use of oxygen are:

a) Driving pneumatic tools,

b) Inflating vehicle tires, rubber boats, etc.,

c) Pressurizing and purging systems,

d) Replacing air or inert gas,

e) Cooling or refreshing the air in confined spaces,

f) A welder who intends to 'cool' himself by blowing oxygen into his clothing,

g) Dusting benches, machinery and clothing,

h) Starting diesel engines.

In each case the fire and explosive risk is the same and results from exposing combustible materials e.g. flammable gases, flammable solids, rubbers, textiles, oils and greases to oxygen.

\subsubsection{Use of Incorrect Materials}

Design of oxygen equipment is very complex and the why and how is not always obvious. In essence nearly all materials are combustible in oxygen. Safe equipment for oxygen service is achieved by careful selection of suitable materials or combination of materials and their use in a particular manner. Any modifications to a design must be properly authorized to prevent incompatible materials being used. Substituting materials which look similar is extremely dangerous and many accidents are reported where the cause was incompatible replacement parts.

\subsection{Combustible Material \\ 2.3.1. In Oxygen-Enriched \\ Atmospheres}

Materials that do not burn in air, including fire resistant materials, can burn vigorously in oxygen-enriched air or pure oxygen.

In enriched oxygen atmospheres the most common combustible material that directly affects safety of personnel is clothing. All clothing materials will burn fiercely in an oxygen-enriched atmosphere. The same applies to plastics and elastomers.

An example of this increased reactivity can be seen below, for a cotton overall material exposed to fire in atmospheres containing increasing levels of oxygen (Fig. 2). Similar curves, indicating the same kind of behavior could be drawn for other materials - in particular for plastics and elastomers.

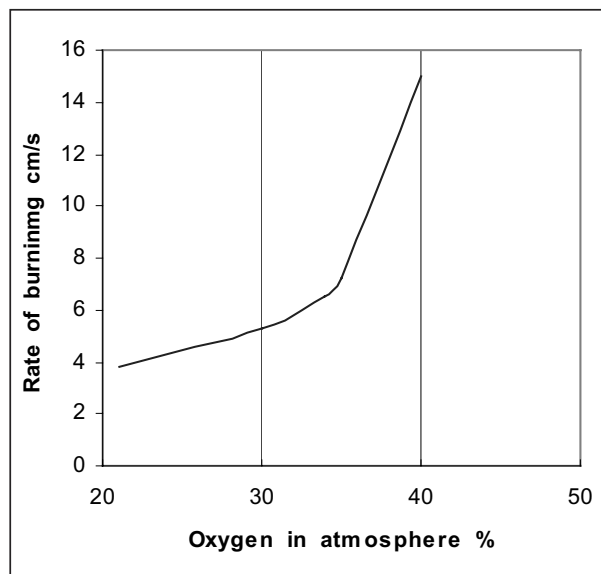

Fig. 2. A cotton overall material exposed to fire in atmospheres containing increasing levels of oxygen

\subsubsection{In Pressurized Oxygen Systems}

In principle all organic materials will burn in oxygen and so do most metals and metal alloys. Pressure affects the behavior of materials, e.g. by reducing ignition temperatures and increasing combustion rates. It is for these reasons that pressurized oxygen systems are only allowed to be constructed from materials and equipment whose design has been approved for the relevant operating conditions.

Oil and grease are particularly hazardous in the presence of oxygen as they can ignite extremely easily and burn with explosive violence. In oxygen equipment, oil and grease ignition often causes a chain reaction, which finally results in metal burning or melting. In such cases the molten or burned metal residue is projected 
away from the equipment and may be followed by an oxygen release. This in turn can lead to fierce and rapidly spreading flames in any adjacent combustible material external to the equipment. Oil and grease must never be used to lubricate equipment that will be in contact with oxygen.

\subsection{Ignition Sources}

\subsubsection{In Oxygen-Enriched}

Atmospheres

Ignition sources in oxygen-enriched conditions could be:

a) Open fires or naked flames (cigarettes, welding or other hot work, petrol driven engines, furnaces etc.),

b) Electrical sparks,

c) Grinding or frictional sparks.

\subsubsection{In Pressurized Oxygen Systems}

In systems containing oxygen under pressure the sources of ignition are not as obvious as naked flames and hot surfaces. The following ignition sources have been identified as having caused fires in oxygen systems:

a) Heating by adiabatic compression,

b) Friction,

c) Mechanical impact,

d) Electrical sparks,

e) High gas velocity with presence of particles,

f) Heating by turbulence.

\section{Prevention of Fires in Oxygen Systems}

\section{Summary of Recommendations}

The more important points which have to receive attention if accidents are to be avoided are:

a) Ensure that people who are expected to work with oxygen, are properly trained and informed of the risks caused by an excess of oxygen.

b) Make sure that the proper equipment is used and that it is leak-tight and in good operational order.

c) Use only materials and equipment approved for use in oxygen. Never use replacement parts which have not been specifically approved.

d) Use suitable clean clothing, free from oil and easily combustible contaminants.

e) Never use oil or grease to lubricate oxygen equipment.

f) Check that all existing fire extinguishing equipment is in good condition and ready for use.

g) When working in confined spaces where oxygen is normally used, isolate the equipment, provide good ventilation and use an oxygen analyzer. Entry shall only be allowed by means of a permit issued by a trained responsible person.

h) Smoking shall be strictly forbidden where there is any possible risk of oxygen enrichment.

i) People catching fire in enriched oxygen atmospheres cannot be rescued by a person entering the area to pull them out, as the rescuer will almost certainly also catch fire.

j) People who have been exposed to oxygen-enriched atmospheres shall not be allowed to approach open flames, burning cigarettes, etc. until after adequate ventilation of their clothing.

Make sure that all oxygen apparatus and equipment is properly identified. Escape routes must be kept clear at all times.

For further information, please consult the source document on the EIGA Website: EIGA (European Industrial Gases Association), Document: Doc 04/00, www.eiga.org

Received: October 3, 2003 